\title{
Editorial
}

\section{György von Békésy \\ 3. Juni 1899 bis 13. Juni 1972}

Zum Gedenken an den 100. Geburtstag des Nobelpreisträgers György von Békésy fand zwischen dem 24. und dem 26. Juni 1999 an der Ungarischen Akademie der Wissenschaften in Budapest eine feierliche wissenschaftliche Tagung unter dem Präsidium von Prof. Ferenc Glatz (Präsident der Ungarischen Akademie der Wissenschaften) und Prof. Elek Straub (Präsident der Ungarischen Telecom Matáv) statt. Anlässlich dieser Tagung, an welcher neben ungarischen Forschern auch verschiedene internationale Persönlichkeiten teilnahmen, wurden neben wissenschaftlichen Themen auch verschiedene Abschnitte des Lebenslaufes von Békésy dargestellt. In der vorliegenden Ausgabe wird eine von Prof. Ribari (Budapest) verfasste kurze Allgemeinbiographie dieses bedeutenden Gehörforschers und Gelehrten wiedergegeben. In einer zweiten in diesem Heft publizierten Arbeit wird speziell auf den Lebensabschnitt, den György von Békésy in Bern verbrachte, eingegangen mit Publikation einer Reihe von bisher unveröffentlichen Dokumenten.

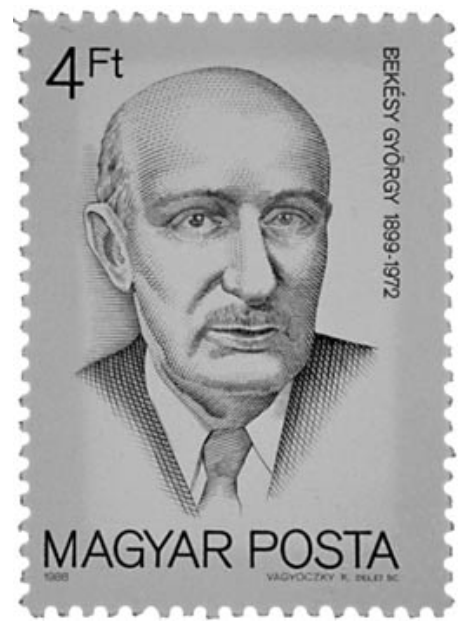

Die Abbildung zeigt die Briefmarke, welche 1988 von der ungarischen Post zum Gedenken an György von Békésy herausgegeben wurde (Dokument freundlicherweise zur Verfügung gestellt von A. Mudry, Lausanne).

R. Häusler, Editor-in-Chief

\section{KARGER \\ (ㄱ) 2001 S. Karger AG, Basel}

Fax + 41613061234

E-Mail karger@karger.ch www. karger.com

Accessible online at: www.karger.com/journals/orn 